\title{
Learning Progressions and Science Practices
}

\section{Tensions in Prioritizing Content, Epistemic Practices, and Social Dimensions of Learning}

\author{
Ashlyn E. Pierson ${ }^{1} \cdot$ Douglas B. Clark ${ }^{2}$ - Gregory J. Kelly ${ }^{3}$
}

Published online: 29 August 2019

(C) Springer Nature B.V. 2019

\section{Introduction}

Tensions have emerged as science education researchers and practitioners have increasingly prioritized students' development of, and engagement in, science practices over students' acquisition of declarative knowledge about science concepts and processes. K-12 science standards, like the Next Generation Science Standards, include modified forms of professional science practices, aiming to represent developmentally appropriate pathways from novice to expert practice (Next Generation Science Standards [NGSS] Lead States 2013; National Research Council [NRC] 2012). Yet authentic engagement in science practices involves more than the replication of professional practices in K-12 contexts. Meaningful engagement in science practices requires that students be positioned as epistemic agents; instead of learning about science, students should appropriate disciplinary tools and processes to figure out the way the world works (Berland et al. 2016; Duschl et al. 2007; VanLehn 2013).

A practice-oriented approach to science education therefore demands shifts in both curriculum and instruction and calls into question traditional models of science learning. In response, the articles in this special issue offer nuanced insights about the implications of practiceoriented learning objectives for the ways that researchers and educators model and analyze learning and design to support learning, and they propose alternatives or adaptations to learning progressions as they are currently conceptualized. In particular, this special issue presents manuscripts that consider: (1) tensions that have emerged as researchers have shifted

Ashlyn E. Pierson

ashlyn.e.pierson@gmail.com

Douglas B. Clark

douglas.clark@ucalgary.ca

Gregory J. Kelly

gkelly@psu.edu

1 Vanderbilt University, Nashville, TN, USA

2 University of Calgary, Calgary, Canada

3 Pennsylvania State University, State College, PA, USA 
their focus from conceptual knowledge to students' diverse and non-linear sense-making practices, (2) disciplinary practices in relation to students' practices and students' epistemic aims, (3) new models for understanding science learning or new perspectives on supporting students' science practices, and (4) implications for learning progressions to support these practices. Our introduction aims to contextualize and synthesize the emergent contributions of these papers and to explore future directions for research about practice-oriented science education and perspectives on learning progressions.

\section{Learning Progressions and Practice-Oriented Science Education}

Science education reform has emphasized increasing K-12 students' engagement in disciplinary science practices, like designing investigations, modeling, and analyzing and interpreting data (NGSS Lead States 2013; NRC 2012). This focus on practices in science education has emerged from interdisciplinary research in science studies. Empirical investigations of scientific communities offer insights about how science is conducted and thus provide models for expanding notions about what counts as disciplinary knowledge in science (e.g., Knorr-Cetina 1983; Lynch 1993; Pickering 1992). From the many science education studies that attend to science studies, important lines of research have emerged (e.g., Duschl et al. 2007), including those that prioritize students' development of and engagement in science practices (e.g., Lehrer and Schauble 2015).

In science education research, this practice turn requires careful consideration of the ways that students can be situated in social contexts to support the appropriation and transformation of disciplinary knowledge and practices (Ford and Forman 2006; Engle and Conant 2010). In order to facilitate the design of learning environments that support students in developing disciplinary practices and epistemologies, researchers have proposed learning progressions for science practices. For example, the Next Generation Science Standards offer developmental trajectories for each of their eight Science and Engineering Practices (NGSS Lead States 2013). As another example, Schwarz and colleagues have developed and refined a learning progression for modeling epistemologies and practices (Fortus et al. 2016; Schwarz et al. 2009; Schwarz et al. 2012).

Challenges emerge, however, in the design and use of learning progressions for science practices. Learning progressions represent overarching aggregate arcs in the curriculum (e.g., Gotwals and Alonzo 2012), which are rarely replicated in individual students' contextdependent and non-linear learning trajectories (e.g., Louca et al. 2004; Svoboda and Passmore 2013). Rather, research suggests that students' ideas, and in turn, the practices that they identify as relevant, shift in response to their task, the classroom environment, and their interactions with the teacher and their peers (Berland et al. 2016; Hammer and Elby 2003; Louca et al. 2004). Pierson et al. (2017) have demonstrated that learning progressions for complex practices, like modeling, do not represent fixed linear pathways through which all students learn; rather, a student may exhibit practices at multiple points along the progression at any given time across different contexts.

These findings raise questions about the utility of learning progressions for practiceoriented science learning (Hammer and Sikorski 2015). For example, are there "successively sophisticated" enactments of practices that might be represented in learning progressions, or are different enactments of practices appropriate in different contexts? Given the contextdependent nature of students' and scientists' practices, could learning progressions serve as evaluative or analytic tools for understanding students' engagement in science practices? 
Similarly, could learning progressions inform the design of learning environments or curricula that support the development of science practices?

The articles in this special issue address these questions in several ways. Some of the articles illustrate the ways that sequential or concept-oriented learning progressions can fall short in terms of describing or designing for learning in practice-oriented contexts, and they offer new perspectives about how science practices and epistemic aims might be systematically supported or analyzed over time. Some of the articles explore the ways that learning progressions could be adapted to better fit practice-oriented learning contexts. Each of these approaches is useful for considering how learning progressions fit with the evolving landscape of science education research. In what follows, we draw on the insights developed in the articles to consider directions for future work.

\section{Supporting the Development of Science Practices}

The articles in this special issue offer a range of perspectives on learning progressions in terms of their utility for supporting the development of science practices. Guy-Gaytán, Gouvea, Griesmer, and Passmore consider teaching in the context of practice-oriented curricula, identifying implications for students' opportunities to engage in authentic science practices. Hardahl, Wickman, and Caiman propose expanding the range of concepts and practices that might be included in learning progressions, arguing that the tinkering and manual labor required to produce phenomena should be taught explicitly as science content. As an alternative to learning progressions, which often background social processes of learning, Pierson and Clark explore co-operative action (Goodwin 2017) as an analytic tool for tracing the development of classroom science practices. Farris, Dickes, Sengupta, and Sikoriski each offer ways to reframe learning progressions to represent heterogeneity in students' ideas, practices, and experiences; Farris and colleagues by taking a phenomenological approach toward learning progressions, and Sikorski by reconceptualizing "upper anchors" within learning progressions. In this section, we synthesize the perspectives proposed in each of these articles to provide a foundation for subsequently integrating and extrapolating on these perspectives to inform future directions for science education research.

Guy-Gaytán, Gouvea, Griesmer, and Passmore explain that learning progressions shape curricular materials, which in turn affect students' development of science practices, and they propose that learning progressions could be further leveraged to support the enactment of these curricula in the context of teacher professional development. They argue that researchers and curriculum developers need examples of what science practices look like in classrooms; otherwise, they will struggle to design curricula that support authentic engagement in science practices, particularly in terms of supporting students' epistemic agency. Focusing on the practice of modeling, Guy-Gaytán and colleagues illustrate tensions between curriculum developers' aims to engage students in modeling as an epistemic practice and teachers' aims to ensure that students are learning about scientific content. They argue that while learning progressions may be useful in designing curricula to support epistemic practices, the enactment of those curricula may not align with curriculum developers' objectives. Specifically, they illustrate the ways that teachers' enactments of practice-oriented curricula can be characterized as what Miller et al. (2018, p. 1056) have described as "complacent enactments" of the practice-oriented instruction, positioning students as passive recipients of science concepts rather than as active collaborators in the creation of new content. 
To illustrate this tension, Guy-Gaytán and colleagues draw on data collected from science classrooms in which teachers are using modeling-based curricula designed with epistemic coherence in mind. In their analysis of these data, Guy-Gaytán and colleagues find that tensions exist for teachers between viewing models as content to be learned by students and viewing modeling as a practice for which the end products are unknown, and they find that teachers who prioritize the former perspective may limit students' opportunities to construct models as tools for their own inquiry. As an implication of their study, they argue that creating curricula based on practice-oriented learning progressions is not sufficient to support teachers and students in engaging in authentic practices in science classrooms. As a solution, Guy-Gaytán and colleagues propose sharing learning progressions that foreground practices and epistemic agency with teachers through professional development as a tool for guiding their goals for students.

Hardahl, Wickman, and Caiman raise concerns about the ways that traditional representations of science learning background important aspects of science practice. They argue that students' practices for producing phenomena are often overlooked in science education research, even though producing phenomena is a key component of professional science. To foreground this component of science practice, Hardahl and colleagues argue that materiality should be explicitly addressed in science teaching and in designs for learning. They argue that practices for producing phenomena, including practices related to tinkering and manual labor, should be explicitly taught as physics content. They argue that this approach makes tacit content accessible to all students and also helps them understand how knowledge is created in science and technology fields.

Hardahl and colleagues' stance implies that learning progressions could be developed to describe a linear process through which students' ideas about producing phenomena might progress. These learning progressions would likely attend to students' epistemic understandings of the role of materiality in producing phenomena. Rather than creating learning progressions that frame producing phenomena as explicit content, another approach might acknowledge that there are important aspects of science learning, like producing phenomena that extend beyond content learning and that researchers and educators should attend to these practices in their designs for learning and in their analyses.

Pierson and Clark highlight another limitation of learning progressions, noting that learning progressions often obscure social processes of learning, instead approaching learning from an individual cognitive perspective. To understand the processes through which students collaboratively build practices and understandings, possibly between levels of learning progressions, they propose leveraging a co-operative action lens (Goodwin 2017) for analysis of classroom science practices. Goodwin (2017) and Lemke (2000) have described the ways that tools and practices in science are reused and transformed over time. Pierson and Clark leverage this lens to analyze longitudinal classroom data, finding that within a classroom, practices are appropriated and transformed (1) immediately, (2) longitudinally, and (3) in interaction with other science practices. In their analysis, they illustrate the ways that students' artifacts and practices become resources for subsequent enactments of practice.

Whereas traditional learning progressions can be used to trace the progress of an individual student, Pierson and Clark demonstrate how a co-operative action lens can be used to trace the progress of a practice as it is appropriated and transformed within a classroom community. They suggest that examining who is able to contribute to the substrate of classroom practices, as well as which practices are able to sediment into the substrate of classroom practices, could be an important indicator of the health of the classroom as a scientific community. Because cooperative action foregrounds aspects of learning often backgrounded in learning progressions, 
they consider these methods of analysis as being complementary, each leveraging different models of learning to understand classroom practices.

Rather than proposing alternatives to learning progressions, Farris, Dickes, and Sengupta offer suggestions for adapting learning progressions to represent the complexity of practice-oriented learning environments. They characterize science practices, like modeling, as enactive and emergent, describing the ways that scientists and students both make meaning through disciplined interpretation, which involves perspective taking, finding patterns, and relying on intuition. Like Guy-Gaytán and colleagues, Farris and colleagues emphasize the importance of positioning modeling as interpretive and knowledge-generative rather than positioning modeling as a way of representing of canonical understandings, and they argue that teachers impact students' science practices as they constrain or expand students' agency along different dimensions. For example, Farris and colleagues illustrate how constraining certain types of agency, like epistemic agency, can deepen other types of agency, such as representational agency.

Farris and colleagues amplify recent calls for researchers and practitioners to attend to the heterogeneity of students' work, and they propose a phenomenological approach for conceptualizing learning progressions. While they do not present a learning progression in their paper, they suggest a starting point for a possible progression based on their data: "positioning students with representational agency to interpret and model measurement data ... they had collected" (p. 4). They illustrate the way that the teacher in their study increasingly extends epistemic and representational agency to the students in her classroom in later learning activities. In their analysis and discussion, they emphasize that future research related to learning progressions in STEM should account for the way that representational and epistemic practices are inextricably linked, while allowing for heterogeneity in students' pathways in developing these practices and epistemologies.

Sikorski proposes several solutions for accounting for heterogeneity in student thinking. Taking a wide lens, rather than focusing on a specific practice, she examines the fundamental structure of learning progressions. She argues that learning progressions should be reconceptualized to reflect the field's increasingly complex perspective of learning in science, in terms of both content and practices. She proposes adapting learning progressions to include context-dependent upper anchors, which, at a minimum, must acknowledge that the "most sophisticated" enactment of a science practice is dependent on context.

Sikorski describes several approaches to accomplish this goal, including treating learning progressions as toolboxes or non-hierarchical lists of ways of thinking, treating upper anchors as cumulative, so that each level includes each lower level, and establishing new upper reaches that attend to students' navigation of context-dependencies or multiple epistemologies. Along with each approach, she also explores associated challenges. For example, treating learning progressions as non-hierarchical limits their potential use as an evaluative or analytic tool for measuring student progress, and treating upper anchors as cumulative problematically frames learning as accretion of knowledge. Though there are challenges associated with each approach, grappling with the affordances and limitations of each could be a productive exercise for science education researchers aiming to make sense of the relationships between and within content-oriented and practice-oriented learning progressions.

Taken together, these articles offer critical and constructive perspectives on the traditional framing of learning progressions in science education, and they offer a range of pathways for science education to move forward - either by adapting learning progressions to fit new aims or by integrating learning progressions with other methods for describing and analyzing practice-oriented science learning. Through these insights, the articles consider constructs 
and analytic methods that may be valuable for research in practice-oriented classroom contexts but are rarely acknowledged in the context of learning progressions research.

\section{Next Steps and Future Research}

The articles in this special issue propose a range of next steps for future research, including adapting the structure of learning progressions to reflect heterogeneity, expanding the content represented in learning progressions to include practices, such as producing scientific phenomena, and incorporating new analytic tools like co-operative action in analyses. In this section, we take a wider lens to consider learning progressions situated within the field of science education. We aim to provide an overview of aspects of learning that may be overlooked by learning progressions and to consider future directions for science education research and practice-oriented science education reform.

Initially, this special issue was conceptualized as focusing on the trajectories of individual students, considering tensions between researches that operationalizes learning as engagement in disciplinary science practices versus the accumulation of science concepts. The articles in this special issue have expanded our attention to include the complex ways that interactions within the classroom community shape individual students' enactments of practices, which are defined, enacted, and transformed within a community. This perspective resonates with literature that characterizes science as practice. Drawing on science and technology studies, Lehrer and Schauble (2015 p. 675) describe the types of scientific reasoning typically represented in learning progressions as a components of larger ensembles of activity. These ensembles include:

Networks of participants and institutions (Latour 1999); specialized ways of talking and writing (Bazerman 1988); development of representations that render phenomena accessible, visualizable, and transportable (Gooding 1990; Latour 1990; Olson 1994); and efforts to manage material contingency by working out the details of instrumentation and measurement.

This image of science highlights its complicated and ever-changing nature. From this perspective, engaging in science does not involve simply acquiring knowledge or developing ability in terms of discrete practices, but also developing ways of expressing ideas (Gee and Green 1998) and participating in changing communities of practice (Lave 1996; Goodwin 2017).

This image of science makes clear that conceptual learning progressions are not sufficient for understanding or designing for students' science learning. Yet even practice-oriented learning progressions may not adequately describe learning within this paradigm. Whereas expert practices have been used to anchor learning progressions (e.g., Schwarz et al. 2012), the articles in this special issue raise questions about which practices researchers and educators should prioritize, the extent to which those priorities are context-dependent, and how to support the development of and engagement in practices that are meaningful to students and the classroom community in which they are situated.

Professional science practices develop and sediment over extended timescales (Goodwin 2017), and they are shaped by scientists' questions and lines of inquiry (Latour 1999; Pickering 1995). Therefore, it is unreasonable to assume that science practices that emerge in K-12 classrooms will exactly replicate professional practices. Moreover, attempting to replicate these practices could lead to ritualized performance of practices for students rather than authentic engagement in inquiry (Berland et al. 2016; Ford and Forman 2006). As a result, it is important for researchers and educators to identify and leverage "seeds" of 
professional science practices in relation to students' everyday practices and epistemologies, "which may only gradually come to resemble the final form that we recognize in professional science" (Lehrer and Schauble 2015, p. 678). This perspective calls into question the approach of anchoring learning progressions with "expert" practices.

Instead, science education researchers and practitioners might attend to progress along dimensions that are not foregrounded in traditional learning progressions, such as the development of classroom scientific communities, for example, or the development of epistemic agency, as proposed by articles in this special issue. These constructs entail attending not only to the knowledge and practices that students develop, but also to the identities they build as participants within classroom communities of practice and within the science curriculum more broadly. Horn (2008) found that disciplinary identities play an important role in students' persistence, and she demonstrates that these identities are constantly reified and transformed throughout students' experience in school. These findings imply a need to better understand the way that students' disciplinary identities develop in relation to their experiences in K-12 science classrooms and in relation to the curriculum more broadly.

While it is possible to imagine a learning progression that describes a pathway toward identity development, the complex network of experience and interaction involved in identity formation (Holland et al. 2003) implies that an aggregate pathway may not be especially useful for the design and analysis of learning environments. Therefore, an important next step for the field of science education may involve reconceptualizing our notion of "upper anchors" for science learning at a minimum, and potentially reconceptualizing how we support students in navigating epistemic pathways, as proposed by Sikorski. In some cases, this work may involve turning to methods beyond learning progressions for understanding students' progress, as proposed by Pierson and Clark. Regardless of whether learning progressions are used to model or understand this progress, further research is needed to understand teachers' and students' interactions with respect to agency as proposed by Farris and colleagues and Guy-Gaytán and colleagues. Furthermore, future research may expand the landscape of relevant practices in science education, as proposed by Hardahl and colleagues.

Taken together, these papers demonstrate ways of integrating disciplinary knowledge and practices in science education. The studies show how individual students' appropriation and transformation of disciplinary practices is situated in complex social interactions that shape students' opportunities for learning as part of a classroom community. Future research should consider not only what is traditionally framed as disciplinary knowledge, but also equally important constructs like identity and community in order to support students' development of and engagement in meaningful science practices.

\section{Compliance with ethical standards}

Conflict of interest The authors declare that they have no conflict of interest.

\section{References}

Bazerman, C. (1988). Shaping written knowledge. Madison: University of Wisconsin Press.

Berland, L. K., Schwarz, C. V., Krist, C., Kenyon, L., Lo, A. S., \& Reiser, B. J. (2016). Epistemologies in practice: making scientific practices meaningful for students. Journal of Research in Science Teaching, 53(7), 1082-1112. 
Duschl, R. A., Schweingruber, H. A., \& Shouse, A. W. (2007). Taking science to school: learning and teaching science in grades K-8. Washington, DC: National Academies Press.

Engle, R. A., \& Conant, F. R. (2010). Guiding principles for fostering productive disciplinary engagement: explaining an emergent argument in a community of learners classroom. Cognition and Instruction, 20, 399-483.

Ford, M. J., \& Forman, E. A. (2006). Redefining disciplinary learning in classroom contexts. Review of Research in Education, 30, 1-32.

Fortus, D., Shwartz, Y., \& Rosenfeld, S. (2016). High school students' meta-modeling knowledge. Research in Science Education, 46(6), 787-810.

Gee, J. P., \& Green, J. (1998). Discourse analysis, learning, and social practice: a methodological study. Review of Research in Education, 23, 119-169.

Gooding, D. (1990). Experiment and the making of meaning. New York: Kluwer.

Goodwin, C. (2017). Co-operative action (learning in doing: social, cognitive, and computational perspectives). Cambridge: Cambridge University Press.

Gotwals, A. W., \& Alonzo, A. C. (2012). Learning progressions in science: current challenges and future directions. Rotterdam: Sense Publishers.

Hammer, D., \& Elby, A. (2003). Tapping epistemological resources for learning physics. The Journal of the Learning Sciences, 12(1), 53-90.

Hammer, D., \& Sikorski, T. R. (2015). Implications of complexity for research on learning progressions. Science Education, 99(3), 424-431.

Holland, D.C., Lachicotte Jr, W., Skinner, D., \& Cain, C. (2003). Identity and agency in cultural worlds. Harvard University Press.

Horn, I. S. (2008). Turnaround students in high school mathematics: constructing identities of competence through mathematical worlds. Mathematical Thinking and Learning, 10(3), 201-239.

Knorr-Cetina, K. (1983). The ethnographic study of scientific work: towards a constructivist interpretation of science. In K. Knorr-Cetina \& M. Mulkay (Eds.), Science observed: perspectives on the social study of science (pp. 115-140). Beverly Hill: Sage Publications.

Latour, B. (1990). Drawing things together. In M. Lynch \& S. Woolgar (Eds.), Representation in scientific practice (pp. 19-68). Cambridge: MIT Press.

Latour, B. (1999). Pandora's hope: essays on the reality of science studies. Harvard university press.

Lave, J. (1996). Teaching, as learning, in practice. Mind, Culture, and Activity, 3(3), 149-164.

Lehrer, R., \& Schauble, L. (2015). The development of scientific thinking. In R. M. Lerner (Ed.), Handbook of child psychology and developmental science (pp. 1-44). Hoboken: Wiley.

Lemke, J. L. (2000). Across the scales of time: artifacts, activities, and meanings in ecosocial systems. Mind, Culture, and Activity, 7(4), 273-290.

Louca, L., Elby, A., Hammer, D., \& Kagey, T. (2004). Epistemological resources: applying a new epistemological framework to science instruction. Educational Psychologist, 39(1), 57-68.

Lynch, M. (1993). Scientific practice as ordinary action: ethnomethodology and the social studies of science. Cambridge: Cambridge University Press.

Miller, E., Manz, E., Russ, R., Stroupe, D., \& Berland, L. (2018). Addressing the epistemic elephant in the room: epistemic agency and the next generation science standards. Journal of Research in Science Teaching, 55(7), 1053-1075.

National Research Council [NRC]. (2012). A framework for k-12 science education: practices, crosscutting concepts, and core ideas. Washington, DC: The National Academy Press.

NGSS Lead States. (2013). Next generation science standards: for states, By States. The Next Generation Science Standards. Washington, DC. Retrieved from www.nextgenscience.org/next-generation-science-standards. Accessed 2 Aug 2019

Olson, D. R. (1994). The world on paper: the conceptual and cognitive implications of writing and reading. New York: Cambridge University Press.

Pickering, A. (1992). Science as practice and culture. Chicago: University of Chicago press.

Pickering, A. (1995). The mangle of practice: time, agency and science. In American Journal of Sociology. Chicago: University of Chicago Press.

Pierson, A. E., Clark, D. B., \& Sherard, M. K. (2017). Learning progressions in context: tensions and insights from a semester-long middle school modeling curriculum. Science Education, 101(6), 1061-1088.

Schwarz, C. V., Reiser, B. J., Davis, E. A., Kenyon, L., Achér, A., Fortus, D., Shwartz, Y., Hug, B., \& Krajcik, J. (2009). Developing a learning progression for scientific modeling: making scientific modeling accessible and meaningful for learners. Journal of Research in Science Teaching, 46(6), 632-654.

Schwarz, C., Reiser, B.J., Acher, A., Kenyon, L., \& Fortus. (2012). MoDeLS: Challenges in defining a learning progression for scientific modeling. In a. Alonzo \& a. W. Gotwals (Eds.), Learning progressions in science: current challenges and future directions. 
Svoboda, J., \& Passmore, C. (2013). The strategies of modeling in biology education. Science \& Education, 22(1), 119-142.

VanLehn, K. (2013). Model construction as a learning activity: a design space and review. Interactive Learning Environments, 21(4), 371-413.

Publisher's Note Springer Nature remains neutral with regard to jurisdictional claims in published maps and institutional affiliations. 